\title{
PARALLEL IMAGE ANALYSIS: THEORY AND APPLICATIONS
}




\section{SERIES IN MACHINE PERCEPTION AND ARTIFICIAL INTELLIGENCE*}

Editors: H. Bunke (Univ. Bem, Switzerland)

P. S. P. Wang (Northeastem Univ., USA)

Vol. 8: Thinning Methodologies for Pattern Recognition

(Eds. C. Y. Suen and P. S. P. Wang)

Vol. 9: State of the Ant in Digital Mammographic Image Analysis

(Eds. K. W. Bowyer and S. Astley)

Vol. 11: Experimental Environments for Computer Vision and Image Processing (Eds. H. I. Christensen and J. L. Crowley)

Vol. 12: Computing Conceptual Organization in Computer Vision (Eds. S. Sarkar and K. L. Boyer)

Vol. 13: Progress in Automatic Signature Verification (Eds. R. Plamondon)

Vol. 14: Document Analysis Systems (Eds. A. Dongel and L. Spitz)

Vol. 15: Parallel Image Analysis and Processing (Eds. K. Inoue, A. Nakamura, M. Nivat, A. Saoudi and P. S. P. Wang)

Vol. 16: Document Image Analysis (Eds. H. Bunke, P. S. P. Wang and H. Baird)

Vol. 17: Applications of Al, Machine Vision and Robotics (Eds. K. L. Boyer, L. Stark and H. Bunke)

Vol. 18: VLSI and Parallel Computing for Pattem Recognition and AI (Ed. N. Ranganathan)

Vol. 19: Parallel Image Analysis: Theory and Applications (Eds. L. S. Davis, K. Inoue, M. Nivat, A. Rosenfeld and P. S. P. Wang)

Vol. 20: Picture Interpretation: A Symbolic Approach (Eds. S. Dance, T. Caelli and Z.-Q. Lin)

Vol. 21: Modelling and Planning for Sensor Based Intelligent Robot Systems (Eds. H. Bunke, T. Kanade and H. Noltemeier)

\section{Forthcoming}

Vol. 10: Generic Object Recognition Using Form and Function (Eds. K. W. Bowyer and L. Stark) 
Series in Machine Perception and Artificial Intelligence - Vol. 19

\title{
PARALLEL IMAGE ANALYSIS: THEORY AND APPLICATIONS
}

\author{
Editors \\ L S Davis \\ Institute for Advanced Computer Studies, University of Manyland, \\ College Park, USA \\ K Inoue \\ Department of Computer Science \& Systems Engineering, \\ Yamaguchi University, Japan \\ M Nivat \\ Universite Paris VII, Cedex, France \\ A Rosenfeld \\ Center for Automation Research, Unversity of Maryland, \\ College Park, USA

\section{P S P Wang} \\ College of Computer Science, Northeastem University, \\ Boston, USA
}




\section{Published by}

World Scientific Publishing Co. Pte. Led.

PO Box 128, Farrer Road, Singapore 912805

USA office: Suite 1B, 1060 Main Street, River Edge, NJ 07661

UK office: 57 Shelton Street, Covent Garden, London WC2H 9HE

\section{PARALLEL IMAGE ANALYSIS: THEORY AND APPLICATIONS}

Copyright $\Theta 1996$ by World Scientific Publishing Co. Pte. Ldd.

All rights reserved. This book, or parts thereof, may not be reproduced in any form or by any means, electronic or mechanical, including photocopying, recording or any information storage and retrieval system now known or to be invented, without written permission from the Publisher.

For photocopying of material in this volume, please pay a copying fec through the Copyright Clearance Center, Inc., 222 Rosewood Drive, Danvers, Massachusetts 01923, USA.

ISBN 981-02-2476-1

Printed in Singapore by Uto-Print 
Foreword

L. S. Davis, K. Inoue, M. Nivat, A. Rosenfeld \& P. S. P. Wang

\section{Parallel Image Analysis}

Data Allocation Strategies for Parallel Image Processing Algorithms

V. Marion-Poty \& S. Miguet

Facilitating High-Performance Image Analysis on Reduced Hypercube (RH)

Parallel Computers

S. G. Ziauras $\mathcal{E}$ M. A. Sideras

Time-Optimal Digital Geometry Algorithms on Meshes with Multiple

Broadcasting

V. Bokka, H. Gurla, S. Olariu, J. L. Schwing \& I. Stojmenović

A Time-Optimal Multiple-Query Nearest-Neighbor Algorithm on Meshes with Multiple Broadcasting

I. Stoica

A Linear Algorithm for Segmentation of Digital Curves

I. Debled-Rennesson \& J.-P. Reveillès

2-D, 3-D Grammars and Automata

Some Notes on Parallel Coordination Grammars

A. Nakamura

Basic Puzzle Languages

K. G. Subramanian, R. Siromoney, V. R. Dare \& A. Saoudi

Cooperating Systems of Three-Way, Two-Dimensional Finite Automata $Y$. Wang, K. Inoue \& I. Takanami

The Effect of Inkdots for Two-Dimensional Automata

A. Ito, K. Inoue, I. Takanami $\mathcal{G} Y$. Wang

\section{Thinning and Tracking}

On Topology Preservation in 2-D and 3-D Thinning

T. Y. Kong 
Two Methodologies to Implement 3D Thinning Algorithms on Distributed Memory Machines

V. Marion-Poty

Analysis and Design of Parallel Thinning Algorithms - A Generic

Approach

Y. Y. Zhang \& P. S. P. Wang

A New 26-Connected Objects Surface Tracking Algorithm and Its Related PRAM Version

L. Perroton 


\section{FOREWORD}

L. S. DAVIS

Institute for Advanced Computer Studies, University of Maryland College Park, Maryland 20742-3251, USA

K. INOUE

Department of Computer Science and Systems Engineering Faculty of Engineering, Yamaguchi University, Ube, 755 Japan

M. NIVAT

Universite Paris VII, L.I.T.P., Institut Blaise Pascal 2 Place Jussieu, Paris Cedex, France

A. ROSENFELD

Center for Automation Research, University of Maryland College Park, Maryland 20742-3275, USA

P. S. P. WANG

College of Computer Science, Northeastern University Boston, USA

The contributions of this volume were presented as invited papers or regular papers for the International Workshop on Parallel Image Analysis held at College Park, Maryland, USA, June 7-9, 1994. This publication contains a selection of papers by prominent professionals and experts mainly from France, India, Italy, Japan and the USA. The contributions can be roughly divided into three parts:

\section{Parallel Image Analysis}

The first paper, "Data allocation strategies for parallel image processing algorithms" by V. Marion-Poty and S. Miguet presents several data allocation strategies used for the parallel implementation of basic imaging operators. The second paper, "Facilitating high-performance image analysis on reduced hypercube (RH) parallel computers" by S. G. Ziavras and M. A. Sideras shows that parallel computers comprising reduced hypercube interconnection networks are definitely good choices for all levels of image analysis. The third paper, "Time-optimal digital geometry algorithms on meshes with multiple broadcasting" by V. Bokka, H. Gurla, S. Olariu, J. L. Schwing and I. Stojmenovic shows that a number of digital geometry problems can be solved elegantly on meshes with multiple broadcasting by using a time-optimal solution to the leftmost one problem as a basic subroutine. The fourth paper, "A time-optimal multiple-query nearest-neighbor algorithm on meshes with multiple broadcasting" by 1 . Stoica presents a time-optimal algorithm that solves the multiple-query nearest-neighbor problem in $O\left(n^{1 / 6} m^{1 / 3}\right)$ time on a mesh with multiple broadcasting of size $\sqrt{n} \times \sqrt{n}$. The last paper in this section, "A linear algorithm for segmentation of digital curves" by I. Debled-Rennesson and J. P. Reveillès presents a new very efficient linear algorithm for segmentation of 
8-connected digital curves based on a definition of digital lines using a linear double diophantine inequality.

\section{2-D, 3-D Grammars and Automata}

The paper, "Some notes on parallel coordinate grammars" by A. Nakamura discusses some properties of parallel coordinate grammars and examines a relationship between the sequential coordinate grammars and parallel ones. The second paper, "Basic puzzle languages" by K. G. Subramanian, R. Siromoney, V. R. Dare and A. Saoudi shows that the emptiness problem for non-overlapping basic puzzle grammars is decidable, and also establishes a hierarchy among the various classes of puzzle languages. The third paper, "Cooperating systems of three-way, two-dimensional finite automata" by Y. Wang, K. Inoue and I. Takanami introduces a cooperating system of three-way, two-dimensional finite automata, and presents several fundamental properties of this system as a two-dimensional language acceptor whose input tapes are restricted to square ones. The last paper in this section, "The effect of inkdots for two-dimensional automata" by A. Ito, K. Inoue, I. Takanami and $Y$. Wang investigates how much the addition of an inkdot to conventional two-dimensional automata increases the ability for recognizing two-dimensional languages.

\section{Thinning and Tracking}

The first paper in this section, "On topology preservation in 2-D and 3-D thinning" by T. Y. Kong presents systematic and fairly general methods of verifying that a given parallel thinning algorithm always preserves topology, for the cases where $8-/ 26$-adjacency is used on the 1 's and 4-/6-adjacency on the 0 's, or vice versa. The second paper, "Two methodologies to implement 3D thinning algorithms on distributed memory machines" by V. Marion-Poty presents two methodologies to implement skeletonization algorithms on MIMD machines, one based on the decomposition of the thinning operator into sub-operators, and the other based on the decomposition of the study domain (image) into sub-domains. The third paper, "Analysis and design of parallel thinning algorithms - A generic approach" by Y. Y. Zhang and P. S. P. Wang presents a generic approach for the analysis and design of parallel thinning algorithms, and describes the procedures for designing 4-subcycle/iteration, 2-subcycle/iteration, and 1-subcycle/iteration thinning algorithms using this generic approach. The fourth paper, "A new 26-connected objects surface tracking algorithm and its related PRAM version" by $L$. Perroton introduces some notions related to surfaces of 18 and 26-connected objects in 3D discrete images, and a new sequential algorithm to extract the surface and contours of 26-connected objects. It also presents a PRAM related algorithm to construct the successor function of the surface graph.

This collection of papers has also been published as a special issue of the International Journal of Pattern Recognition and Artificial Intelligence (Vol. 9, Nos. 4 and $5,1995)$. We wish to thank all the authors for their contributions and the members of the program committee, without whose help this volume is impossible. 